\title{
Ideology and Textual Analysis Modes in College English Teaching
}

\author{
Wensheng Deng \\ Department of Foreign Languages, Beijing Institute of Petrol-chemical Technology, China \\ Ke Zhang \\ Department of Foreign Languages, Beijing Institute of Petrol-chemical Technology, China
}

\begin{abstract}
Ideology has been infiltrating into texts. So has Western ideology extended into texts adopted in college English course book in China. As it is known to the world, there are conflicts and contradictions of ideology between China and some Western nations. Therefore, it is vital for English teachers to distinguish derogatory ideas from the Western ideology, guised under the cover of course book in the course of teaching. The paper, based upon The Diamond Necklace written by Guy De Maupassant, a French novelist, and "Unit 1 The Pursuit of Dreams, Deaf DJ" from New Progressive College English Integrated Course (Vol.1), is going to exploit the issue of ideology hidden in the texts respectively. The author of the paper puts forward three textual analysis modes to expose the ideologies, i.e. first, plot mode for fictional text; second, thematic mode for non-fictional one; third, qualitative mode for a mixed genre of fictional and non-fictional text. The three modes can be viewed as complementary, which can be used either together or separately depending upon the situation.
\end{abstract}

Index Terms - ideology, college English teaching, textual analysis mode, control

\section{INTRODUCTION}

Ideology infiltrates everywhere, so has it been infiltrating into textbooks. (Michael W. Apple, 2004, pp.59-98) And, if the textbook is compiled in a foreign language, according to the independence of language and thought claimed by Sapir-Whorf hypothesis, it will be filled with foreign ideologies, i.e. foreign thoughts or ideas. Faced with the issue of ideology, maybe, someone will immediately refute my opinion, and shrill, "You are too exaggerative; it's just a teaching medium, nothing political, how could there be ideology in it?" The doubt demonstrates that someone is unknown to ideology, and he is ignoring or denying it. Actually, among some Western nations, such kind of ideological conflicts between social systems have been continuing for more than 150 years since communist theory was formally put forward in The Communist Manifesto by Karl Marx (1818-83) and Frederick Engels (1820-95) in 1848. For instance, disintegration of USSR in 1991 and upheaval of Eastern Europe in 1989, are very good cases in point to prove the conflicts still existed up to now. Similarly, ideological conflicts and confronts between communist China and some of capitalist Western nations have been surrounding us anywhere since New China was established in 1949. The two types of ideas are antagonistic; and the West nations have tried exhausting all efforts to subvert China because China and West have antagonistic social institutions and systems. In other words, the fundamental foundations of the two systems are differently oriented. China is for majority of citizens, the other, the West nations, for small minority of society. In order to subvert China like the former USSR or Eastern European nations, Western capitalist ideologies have changed its channels and vehicles into China. They have been exporting and transferring Western cultures, hard or soft ones, into the antagonists. The strategy of cultural export, such as all kinds of cultural products, life styles, political opinions, or high technology, etc., is the first choice for the people are unconscious of the ideological influence. But, the exportation, essentially, is cultural sabotage or invasion against China. They aim to adolescents for they haven't grown matured enough to possess a pair of critical eyes to distinguish true form wrong. Hence, English textbooks, chosen as sites or battlefields of the conflicts, can't help but be affected by the ideologies, either. This is self-evident. Even British linguist Paul Simpson has addressed such an idea on it, "In fact, no academic study, and certainly no description of the language of texts, can be neutral and objective, for the sociocultural positioning of the analyst will mean that the description is unavoidably political.'(Paul Simpson, 2005, pp.18) The statements quoted here may explain that the text, adopted by English teachers in China, is also suitable to the case with no exception. That is to say, a text isn't transparent or neutral but political as well. Though they are only used as materials for teaching and learning, not for political propaganda, they can hardly resist the ideological influence or dominance. The situation agrees with what a saying describes: If one touches pitch and he will be defiled, which means one is unconsciously influenced by what he is frequently exposed to. Therefore, it is hard for English teachers to avoid the ideology influence disseminated by the text, and he will be affected more or less. But, rationally, as a teacher of English in China, we must find the ideology hidden behind text and resist it, and make an ethical evaluation.

Herein, the paper is going to explore the problem. It consists of two parts, one is the summary of theory of ideology 
and education from sociological perspective, the other part, based upon the theory, citing The Diamond Necklace written by Guy De Maupassant (1850--1893), French novelist, and "Unit 1 The Pursuit of Dreams" from New Progressive College English Integrated Course (Vol.1) as an analysis sample, ${ }^{1}$ is to focus on the ideology dispersed into texts correspondingly, and explore thematic analysis mode of the text in teaching. By doing so, the author of the paper hopes to shed some light to teachers and students with some kinds of modes to distinguish ideology disguised in the text.

\section{PASt And PRESENT OF IDEOlogy StUdies}

Generally, the study of ideology is far more comprehensive and remarkable in the West than in China. The term ideology was coined by Destutt de Tracy (1754-1836), the French philosopher, to describe the science of ideas: that is, the discipline that would enable people to recognize their prejudices and biases. (Dani Cavallaro, 2007, pp.75) His theory has been the fountain of ideological studies. Then, it was studied repeatedly in the later by a body of philosophers, such as Rene Descartes (1596-1650), Immanuel Kant (1724 -1804), G. W. Friederich Hegel (1770-1831), Karl Marx (1818-83) and Frederick Engels (1820-95). The giant philosophers mentioned here have examined the theory from all aspects and made divergent interpretations about it. Some stresses its spiritual orientation, others from its material one, someone else from political one; and other focuses on the studies are moral, ethical and scientific, etc. Throughout modern times, philosophers have been interested in the idea all the more, like Georg Lukács (1885-1971), Antonio Gramsci (1891-1937), Louis Althusser (1918-1990) and Jacques Derrida (1930-2004), et al, have pushed forward the studies further. For example, Gramsci's hegemony theory, Althusser's theory of Ideological State Apparatuses (shortened as ISAs); they are accepted as the ground to resolve problems theoretically and practically. Late as it is today, we may boldly claim that Cultural Revolution (1966-1977) in China was affected by the series theories of ideology because they have controlled the soul and mind of the people. As much as all of them have been investigating the issue with diverse orientation, they share one of fundamental concerns with each other: why do average people easily and eagerly accept and internalize the conditions which they know to be disadvantageous to them? Or relatedly put in another way: why do average people end up with investing in their own unhappiness and put up with the oppression because of the marginal pleasures this may bring with it? In seeking to answer the questions, critics and philosophers have proposed various definitions of ideology. The main ones are listed as follows:

- a body of ideas, ideals, values or beliefs;

- a philosophy;

- a religion;

- false values used to keep people under control;

- a set of habits or rituals;

- the medium through which a culture shapes its world;

- ideas promoted by a specific social class, gender or racial group;

- the values that sustain dominant structures of power;

- the process whereby a culture produces meanings and roles for its subjects;

- the alliance of culture and language;

- the presentation of cultural constructs as natural facts.

(Dani Cavallaro, 2007, pp.76)

From the definitions given above, we can understand ideology is multiple-dimensional concept. It reflects the ideas or voices from various classes or groups in society because it can penetrate into aspects of daily life. But, the ruling class always tries to exploit ideology to control other parts of the society; they exhaust all means to legitimate their ideologies to safeguard against other exploited groups, not merely from political dimension but also various ones related with the existing national sovereignty. So, the people who regard ideology as something merely political are one-dimensional, extremely radical and risky.

Frankly, the studies of ideology in China are less influential than the West. To the author's knowledge, there are some fragmentary discussions of it. They are not systematic, loosely dotted in journals and newspapers. And, the understanding or discussion is centralized around the opinions of Karl Marx and Friederich Engels or Vladimir Lenin (1870-1924), the first founder of USSR; to quite a lot of intellectuals' understanding, ideology refers to only political ideology. Probably, this is mainly resulted from the Cultural Revolution (1966-1976) in China, which has brought about at least three folds of effects: first, it had involved a large number of scholars into conflicts of classes, and they were persecuted or tortured; it left incurable scars to them mentally and physically; second, the shadows brought about by the political movement have made the scholars unwilling to set their foot upon ideology, especially political ideology; third, most of intellectuals have mistaken ideology as political since the Revolution.

Based on the survey of ideology studies discussed above, we can arguably get the characteristics as subsequent entries:

1. Of being class or caste, it refers to ideology is the ideas to represent some class or group in society;

1. Ji, Peiying \& Feng, Yu. (co-ed., 2017). New Progressive College English Integrated Course (Vol.1). Shanghai: Shanghai Foreign Language Education Press. Unit 1 The Pursuit of Dreams is taken from the Vol.1, pp.12-33. 
2. With interests, this means ideology can meet the common demands of some classes or groups, or bring about interests to the classes or divisions;

3. Practicality, it refers to ideology derives from practice in reality on one hand, it also means it is guideline to practice for certain class or group;

4. Of being group, it refers to ideology is embodiment of group appeals, individual voices combined together;

5. Penetrability, this refers to ideology can infiltrate aspects of daily life in society to influence average citizens unconsciously.

(Chen Shuya, 2012, pp.32-36)

\section{IDEOLOGY AND ENGLISH TEXTBOOK}

There are more in-depth researches focused on ideology and education in West than on ideology and English. Roughly, the study between ideology and education is called Sign Control Theory or Sign Domination Theory, which are embodied by a bunch of scholars or educators related to the studies. (Shi Lina, 2013, pp.25-35) One of them is J. P. Gibbs, British scholar of sociology; he divides social control into five types. He defines "social control" as some part of groups deliberately manipulates others in society by some kinds of mediums. The controllers make full use of national powers and verbal signs to dominate others of the society. The use of verbal sign, i.e. education or cultivation for human beings, essentially functions to dominate the human mind and moral value. Basing on Gibbs, J. Eggleston further divides curriculum and social control into two dimensions: first, a society is the dominator of curriculum; second, a society is controlled by curriculum, which is dominated by ruling classes in a society. Other educators, like Basel Bernstein, Pierre Bourdieu, Raymond Williams, Michael W. Apple, M.F.D. Young, all have contributed to the development of the studies greatly. Bernstein puts forward Code Theory of Education Knowledge; Bourdieu has Culture Capital Theory, Williams' Selective Tradition, Young's Theory of Knowledge and Control, and Apple's Theory of Culture and Politics. The series of theory are sources of ideology and education.

The studies of ideology and language, so far as the author is concerned, Paul Simpson, British linguist, is one of representative scholars on the research. His work, Language, Ideology and Point of View (2005), interprets the relationship between ideology and English texts. Based on critical discourse analysis, the book offers all kinds of linguistic modes to distinguish ideology permeated throughout the lines. Combining with discourse analysis, stylistics and cultural studies, he provides readers with insights to understand his thesis. Simpson is comprehensive and analytic.

However, the study in China is just at its initial stage. There are not many scholars who have focused on it, though they mention some relations between ideology and English textbook. We have diverse editions of Syllabus for English Teaching, ${ }^{2}$ which attach the importance of ideology to text-editing and teaching, to teaching methodology and textbook, text-selected and political background home and abroad, etc. Every level of Education ministry has paid heed to the ideology in English course-books. They have special watchdog committees to censor it in order to reduce Western ideological impacts to the least.

\section{Textual Analysis Mode of IDEOlOGy}

\section{A. Plot Mode}

As we have seen in the fore-explained section, the foreign studies are comprehensive on the ground of ideology and education, for which even have brought about a new discipline, curriculum sociology (the author's emphasis) to be established for some time. The theories given by them are of great significance and frames of reference for Chinese scholars, who are striving to put them into practice to resolve the issues in English text for Chinese learners. Like the theory of class ideology by Marx and Engels, Gramsci's hegemony theory, Althusser's theory of Ideological State Apparatuses (shortened as ISAs), code theory of education knowledge by Bernstein, culture capital theory by Bourdieu, Williams' selective tradition, Young's theory of knowledge and control, and Apple's theory of culture and politics, they are very popular and of guidance in the studies to them. As it is known to the world, there have conflicts of ideologies between China and some Western nations. Moreover, English is a required curriculum for every college student. We should have paid enough attention to English texts, as a kind of cultural capital, to resist Western ideologies to dominate the young generations. So, the following parts, hereafter, are going to discuss textual analysis modes of ideology, based on The Diamond Necklace and Unit 1, taken from New Progressive College English Integrated Course (Vol.1).

In the author's eyes, there are three modes to distinguish the ideology from the lines of a text. One is plot mode for fictional text; the other is theme mode for non-fictional one; third, qualitative mode of event for a mixture of the two genres. Plot, according to Aristotle, is "the imitation of the action, as well as the arrangement of the incidents." (J.A.Cuddon, 1999, pp.676) Here, specifically, plot is referred to the action of a tragedy by Aristotle; and in the textbook as college English there are not many cited tragedies but more extracted novels. So, another definition of plot, given by E. M. Forster, British novelist, in his work Aspects of the Novel (1927), is more accountable and serviceable, explains that "...a plot is also a narrative of events, the emphasis falling on causality." (J.A.Cuddon, 1999, pp.676) Hence, according to the explanation, first, we must understand what series of plots there are in a text, including

2. There are different versions of Syllabus for English Teaching in China (1962, 1980, 1985/1986, 1999, 2004). 
sub-plots and events comprising a plot. Taking The Diamond Necklace by Guy De Maupassant as an example to illustrate the procedures to discuss the ideologies permeated in the text. The main plot, i.e. arch plot, in the story goes as follows:

Mr. Loisel and Ms. Mathilde, a shabby couple, were invited to attend the evening party hosted by the Minister of the Ministry of Education. They borrowed a necklace from a friend, Madame Forestier, for the party; unfortunately, they lost it unconsciously on the way home. So, they have to borrow large sum of money from friends and families to buy a new one to return it to Madame Forestier. To pay off all the debts, she has been laboring, and living a frugal life, for entire ten hard years. To her shock, they found that the necklace they had borrowed ten years ago was nothing but one with fake diamonds. ${ }^{3}$

From the main plot, we can catch at least two points, one is Madame Mathilde is a woman with strong vanity; e.g. "It annoys me not to have a single piece of jewelry, not a single ornament, nothing to put on. I shall look poverty-stricken. I would almost rather not go at all. "“...there is nothing more humiliating than to look poor among other women who are rich." (Guy De Maupassant, The Diamond Necklace, pp. 331) The speech addressed by Mathilde is evident enough to display her vanity. The other point is the nation the heroes are living in is one with highly respected contract. The former is easily understood because the poor couple borrowed a necklace for the party, and from a sub-plot of the story we find that they especially bought an evening gown, too. All the actions, including all kinds of events, acts, caused by Mathilde here, are very good cases in point. Mathilde's idea, more or less, is a reflection of ideology of class and caste in French society, which is prevailed and dominated by French bourgeois' life style. From the text, we know that the subsequent items are popular at the time:

1.Regularly hosting a kind of party, which requires attendants to comply with a series of rituals and rites for upper-classes, for instance, a female participant must be good-looking, gentle-lady like, wearing all sorts of ornaments to show off her dignity, elegance, noble origin and status;

2. In a party, usually, a good-looking woman is more sociable, and she would be regarded as a pride by her husband, lover or mistress; the party is held as a means of communication, or a step to enter into a privileged class or group;

3. Throughout a party, dancing or having a dinner is required and popular, so attendants, male or female, are good at dancing and familiar with the events or fashions prevailing in middle and higher society, for which are frequently cited as subjects or topics in conversations. An event or act of the story, like "All the attaches of Cabinet wished to Waltz with her", illuminates that dancing is one of links to host an evening party.

The latter part, that is, the nation, herein, France is specifically referred to, is one country with highly respected contract. The idea of contract is dotted through the lines after the Loisel's company lost the borrowed necklace. A reader can perceive it by thinking for a moment. After they lost the necklace, they borrowed large sum of money to buy another one to return it to the owner and friend Madame Forestier as well. The quotation cited in the following could be evident to prove the thesis.

"Loisel possessed eighteen thousand francs which his father had left him. He would borrow the rest. He did borrow, asking a thousand francs of one, five hundred from another, five louis here, three louis there. He gave notes, took up ruinous obligations, dealt with usurers and all the race of lenders. He compromised to all the rest of life, risking signing a note without knowing whether he could meet it, (the author's emphasis) and frightened by the trouble yet to come, by the black misery that was about to fall upon him, by the prospect of all the physical privation and moral tortures that he was to suffer, he went to get the new necklace laying upon the jeweler's counter thirty-six thousand francs. "(Guy De Maupassant, The Diamond Necklace, pp.334) ${ }^{4}$

From the excerpts given above, the word "borrow" is used twice; the acts or the actions which are similar to "borrow" are ten. Of course, the description here has vividly portrayed Loisel's suffering to beg somebody humbly in order to borrow any money. Moreover, if we extend the thinking, we could regard Loisel's acts as a negotiation with others to sign a contract of IOU. As it is known to the world, French philosophers, Rousseau, Montesquieu, and Voltaire reacted to the social conditions they saw and sought to establish universal rights of man. Among all the theories they have advocated, the concept of contract, put forward by Rousseau, is welcomed deeply into the human mind. The series of theory, hammered out by French thinkers, have been accepted by the world as a foundation of political systems to establish a modern nation. If we compare Loisel's case with whatever in China, we might say, there is a long way to go for us to construct a nation with modernity.

Then, embarking upon the main plot, i.e. the Loisel's company has been laboring for ten years to pay off the debts. The text delineates the heroine's endurance, violent effort and responsibility. During the ten years, her identity is turned upside down; but she has never given up a ray of hope for future. So, the theme of story is dually dimensional: first it is an irony to her vanity; second, it is an image of her persistence, loyalty to both family and society, and victory. From all the plot and events concerned with Mathilde, she is no secondary to her overwhelming surroundings, no "second sex" though she is female. (Simone de Beauvoir)

3. The plot is summed up by the author, based upon The Entire Original Maupassant Short Stories by Guy, de Maupassant. (Trans. by Albert M.C. Mcmaster, B.A.A.E.Henderson, BA.MME. Quesader and others. Prepared and Published by: E-Books Directory,com)

4. Maupassant, Guy, de. (Trans. by Albert M.C. Mcmaster, B.A.A.E.Henderson, BA.MME. Quesader and others). The Entire Original Maupassant Short Stories, pp. 331, 334. Prepared and Published by: E-Books Directory, com. 
Further, if a reader of the text can focus on some of the sub-plots, and integrate them well together, surely, he will have an integrated picture or notion of the nation: it is a modern nation. First, the life style of average people is modern or a kind of modernity, such as taking a walk after supper, hosting a party of communication, taking a taxi "to the cab companies"; second, concept of contract is accepted deeply into the minds of ordinary citizens; third, modern media and state governance, like newspaper and advertisement and companies etc. Moreover, there is Ideological State Apparatus--police station.

\section{B. Thematic Mode}

Thematic mode is most frequently employed in analyzing ideologies of a text. That is, we probe the ideologies hidden between the lines according to the theme expressed in a text. First, we have to summarize what is the theme of a text after we read it again and again. So, what is theme? A theme of a work, properly speaking, is not its subject but rather its central idea, which may be stated directly or indirectly. (J.A.Cuddon, 1999, pp.934) They are ideas about the human condition that we draw from works of literature- not just from fiction but from literature in all genres. (Kelley Griffith, 2006, pp.32) The definition explicates that a theme is subjective ideas of a text by the author of a text. If there is no plot in a text, we must grasp and grip with main events in it. By doing so, we can discover the ideologies hidden beneath the verbal signs, including pictures, illustrations or figures of designs. Taking Unit 1 The Pursuit of Dreams, Deaf DJ as an example to illuminate my arguments. The theme of the text tells us a story of Robbie Wilde, a deaf guy. He loves music very much, especially he dreams to be a DJ though he is deaf. He has overcome all kinds of difficulties and his dream has come into true at last. Therefore, the theme conveys us a clear idea: only if a man has a dream and takes his action, whatever difficulties he is faced, his dream is sure to be realized one day. Obviously, the text wishes the narrator of the story, Robbie Wilde, can be an example for Chinese college students to follow. From the theme of the text, i.e. learning materials, it is available to reach the goal, i.e. an encouragingly didactic story. It is an ideology embodying heroism and optimism.

Second, we must have a clear idea about the textual structure so that we can understand what each part means. For instance, the author of the paper divides the text Unit 1 into three parts: Part 1 tells us that Robbie Wilde likes the music and was influenced by his father, a DJ, when he was a kid and wants to be a DJ; Part 2 selectively describes how he overcame his suffering from losing hearing in the course of fulfilling his dream; Part 3 explicates briefly that he is dedicated to charity and has encouraged young kids to pursue their dream. Basing on the summaries listed here, the text displays the following ideas:

1. A kid's dream is influenced by his family, and vital to his growth;

2. Enduring hardship and making use of high-technology are keys to the fulfillment of one's ideal;

3. A successful man is popular and great only if he is devoted himself into helping others in need;

Besides, we should be excellent at exploring facts and acts through non-fictional type of text; that is, analyzing some statements in a text, decoding the signs, verbal or pictorial.

E.g.1. "We didn't have health insurance at the time and when I got a third infection, my parents couldn't pay for the treatment. I went deaf in my right ear..." (Excerpted from Unit 1 The Pursuit of Dreams, Deaf DJ, pp.14) The statement implies that USA is not a paradise for everyone but for the rich people, because Robbie's hearing impairment is partially due to inability to pay for treatment, which is a kind of indirect criticism of the health care against USA.

E.g. 2. "I loved listening to Metallica, Led Zeppelin, Bob Marley, Michael Jackson. My dad was a DJ, so he played disco, folk, dance, rock, and music from other countries." (Excerpted from Unit 1 The Pursuit of Dreams, Deaf DJ, pp.14) ${ }^{5}$ The text quoted here reveals that entertainment industry is very popular, especially music show, which means a sort of entertainment society has come into being and producing and consuming of entertainment are push and draw of the society.

Third, we can get ideas from topic sentences of each part in a text, which is usually located in the beginning or the end of a text. If there is no topic sentence for each part, key words are best markers to dig out the hidden ideologies between the lines.

\section{Qualitative Mode}

Qualitative mode, from my viewpoints, is also an approach to the text mixed with two types of genres, i.e. fictional and non-fictional, to discover ideologies hidden beneath a text. As to such kind of text, besides the two ways explored above, we can try qualitative mode to grope ideologies implied in the lines. Here, a qualitative mode refers to the category of events or occurrences in a text, similar to the category of subject, such as love, dream, independence, patriotism, eco-system protection, technology and science or devotion and the like. Like Unit 1 The Pursuit of Dreams Deaf DJ, we could infer the theme conveyed by the title of the unit, by which belongs to the category of subject dream-fulfilling. The subject is a reflection of fulfillment of individual dream, i.e. individual value, more concretely speaking, a kind of individualism, is exposed to us, which is exactly suitable to propaganda and encourages college students of China to implement personal ideal, maximize the value, and become a healthy well-being physically and mentally. Sometimes, if the title of a text is not clearly enough to express a theme, such as "The Diamond Necklace", it

5. Ji, Peiying \& Feng, Yu. (co-ed., 2017). New Progressive College English Integrated Course (Vol.1). Shanghai: Shanghai Foreign Language Education Press. Unit 1 The Pursuit of Dreams is taken from the Vol.1, pp.14. 
is hard for us to classify it into whichever category qualitatively. If so, we should read the text repeatedly and find the key events of the text, make sure why, what and how in them. Take the main chain of events in "The Diamond Necklace" as an example listed as below to illustrate my ideas:

The main events chain of the story (what):

1. The Loisel couple is invited to attend a party (the wife, Mathilde has no necklace but to borrow one);

2. Mathilde lost the necklace for her being carelessness;

3. The couple has to borrow large sum of money to replace the necklace;

4. The couple has to work hard for ten years to pay off the debts.

The events given here are only part and parcel of the chain of events in the story.

The root of ten-year endurance (why) of the couple:

1. The couple is extremely boastful, vain, and always pretends to be elegant, dignified in public;

2. The way to replace the necklace and the debts (how):

The couple borrowed large sum of money to replace it, and has been living a shabby life, in a small flat, laboring to do all kinds of jobs they can to earn every franc; such a life style lasted for ten years;

As is discussed above, by taking why, what and how into account, we are certain to give a comparably fair judgment of an event; and all the events integrated together in a text will explicitly express some ideas and can help us make decisions for the elementary events of a text, and notice the dominant ideas in a piece of work; the integrated idea of the events is part of the main theme. In brief, the principle to utilize the mode starts from a text's title to get the category of subject first; second, demarcating the category of an event one by one; third, from the sum of all events integrated together to catch the category. The category is essential in the mode to find ideologies.

\section{CONCluding REMARKS}

The three modes discussed above are merely preliminary ones to explore ideologies disguised in text signs. They can be viewed as complementary, which can be used either together, in an integrated way, or separately, one by one, depending upon the situation. Besides the three modes, there are other approaches to further exploit in analyzing ideologies, like from a perspective of media, journalism and cultural and political studies. Only if we are conscious and careful in teaching, especially in teaching English, for English language is a coat and an instrument of transmitting culture or knowledge, the users are easy to be deceived, we can find ideologies coated with all kinds of shapes and unveil all the ideological harms to students, and resist them completely.

\section{REFERENCES}

[1] Apple, Michael W. (2004). Ideology and Curriculum (Third Edition). New York \& London: Routledge Falmer, pp.59-98.

[2] Cavallaro, Dani. (2007). Critical and Cultural Theory: Thematic Variations. New Jersey: The Athlone Press, pp.75, 76.

[3] Chen, Shuya. (2012). Ideology and Ideological Cybernetics. (Ph. D. dissertation). Henan University, pp.32-36.

[4] Cuddon, J.A. (Revised by C. E. Presto, 1999). The Penguin Dictionary of Literary Terms and Literary Theory. London: the Penguin Group, pp.676.

[5] Griffith, Kelley. (2006). Writing Essays about Literature-A Guide and Style Sheet (Seventh Edition). Peking: Peking University Press, pp.32.

[6] Shi, Lina. (2013). Ideology, Value orientation and Material Election in College English Textbooks-from the Social Perspective of Education. (Ph. D. dissertation). Fudan University: pp.25-35.

[7] Simpson, Paul. (2005). Language, Ideology and Point of View. London: the Taylor \& Francis e-Library, 2005, pp.18.

Wensheng Deng was born in Anhua County, Hunan Province of China in 1967. He received his M.A.in literature from Central South University of China in 2002, and he has further trained his academics at Harding University of the USA from 2007 until 2008. And now he is Associate Professor of Anglo-American Literature of the Dept. of Foreign Languages at Beijing Institute of Petrol-chemical Technology, China. His scholarly studies cover English teaching Comparative Literature, Translation Studies, Film Studies and Politics.

Mr. Deng is a member of Chinese Association of Foreign Language Teachers. And he has published more than 40 papers home and abroad.

Ke Zhang was born in An Qing city of Anhui Province of China in 1978. She got her M.A.in literature of Russia and linguistics from Capital Normal University of Beijing of China in 2002. She is interested in movie analysis, western culture etc. Current ly she is a lecturer of the Dept. of Foreign Languages at Beijing Institute of Petrol-chemical Technology, China. She has also published lots of papers home and abroad. She is a member of Chinese Association of Foreign Language Teachers. 